\title{
Variants of Cloze-Test Based Tasks and Vocabulary Achievement
}

\author{
Zachary Farouk Chai ${ }^{*}$, Suyansah Swanto, Wardatul Akmam Din \\ Faculty of Psychology and Education, Universiti Malaysia Sabah, Malaysia
}

Received March 26, 2020; Revised May 4, 2020; Accepted May 27, 2020

Copyright $(2020$ by authors, all rights reserved. Authors agree that this article remains permanently open access under the terms of the Creative Commons Attribution License 4.0 International License

\begin{abstract}
Vocabulary is an integral part of a language and language education. In view of the close relationship between vocabulary knowledge and language learning, there is a significant need for language learners, especially in the ESL context, to develop, enrich and master their vocabulary in order to be proficient users of the language. ESL teachers could help learners acquire vocabulary knowledge if they have the pedagogical knowledge on how vocabulary may be learned and taught effectively. The study aimed to determine Malaysian primary school learners' vocabulary achievement by using cloze-test based tasks. A total of five primary schools from Sabah, Malaysia were selected in this study. The total number of research participants was 135 and they were at low to intermediate level of proficiency. This study made use of four different cloze-based passages as research instruments in assessing learners' vocabulary knowledge. This research primarily concerned on the descriptive data in the form of frequency and percentage of the learners' vocabulary achievement scores and qualitative data from semi-structured interview. The findings of this study revealed that the research participants scored well in the fourth task whereby cloze-based passages were given along with general pictures and multiple-choice items. A significant correlation between these four variants of cloze-based task with the learners' vocabulary achievement was established. The main pedagogical implication of the research is that teachers should ponder what type of variants to be used in vocabulary task as this could enhance ESL learners' vocabulary achievement.
\end{abstract}

Keywords Cloze-based Tasks, Multiple-choice Items, Pictures, Vocabulary Achievement

\section{Introduction}

Language is used to communicate ideas, thoughts and experiences in our daily life. As we are moving towards a globalised world of education, learners need to master English language as part of their learning development. The acquisition of vocabulary is seen as an imperative aspect of learning English language in formal education. Without a strong vocabulary knowledge base, one would face difficulty in understanding information conveyed through communication. Cameron (2001) states that vocabulary is one of the knowledge areas in English language and it plays a vital role for learners in acquiring a language. Hence, when learners especially those who study in primary school have mastered English vocabulary in the syllabus and English textbooks, they are expected to be able to communicate, write and comprehend effectively.

In Malaysia, the English Language Curriculum for Primary Schools has an important aim to equip primary school learners with basic language skills to enable them to communicate effectively in different contexts that are appropriate to the learners' level of development (Ministry of Education Malaysia, 2011). In other words, the aim of teaching the English language in primary school is to produce learners who are able to communicate effectively in a variety of contexts be it in spoken and/or written forms. Thus, for learners to communicate effectively after their schooling years, vocabulary knowledge plays an essential role in general language ability.

\subsection{Background of the Study}

Vocabulary is fundamental to language and an important aspect of second language learning (Zimmerman, 1997). In relation to this, Richards \& Rodgers (2001) claims that the building blocks of language learning and interaction are not grammar, notions, roles, or some other planning and teaching structures, but rather lexis, which is made up of combinations of terms and letters. In view of this close relationship between vocabulary knowledge and language 
learning, the former is indeed an important factor in language development. Harmer (1991) opines that vocabulary is the key component of language and hence learners need to develop and master their vocabulary to enable themselves to use the language more competently.

In modern classrooms, vocabulary knowledge may be taught through teaching techniques such as, inter alia, multiple-choice questions, words associations, matching items, items rearrangement, completion of word and formation tests. Each of these techniques has its own advantages and disadvantages. Multiple-choice questions, for example, are preferred by many teachers because of their convenience and objectivity. Vocabulary teaching can be carried out in a context-independent and context-dependent manner. In a context-independent vocabulary teaching, words are presented to learners in isolation and it requires them to select the meanings of words without reference to any linguistic context (Mei, 2007). While context-dependent vocabulary teaching includes contextual information in its task to assist learners in producing the expected response. In context-dependent vocabulary tasks context can be presented in sentences or passages (Mei, 2007).

\subsection{Statement of Problem}

ESL teachers and learners know that vocabulary is essential for the development of English proficiency. To make the best use of classroom time, educators need to make informed decisions about what teaching techniques to use to help their learners gain vocabulary skills as effectively and efficiently as possible, but teachers often do not have a clear understanding of this issue (Paul, 2007). This lack of understanding could have an impact on learning in that learners would not actually learn and acquire the vocabulary they have been taught. Therefore, teachers who teach vocabulary but have little knowledge on how to teach it effectively run the risk of using valuable classroom time to teach learners about terms they have had already known (Stallman et al., 1989).

Most primary school learners experience considerable difficulty in processing textual data, particularly in their attempts to understand and acquire new vocabulary. A study by Chen et al., (2016) revealed that a lack of vocabulary in English language lesson was one of the factors that affect learner's reading comprehension. Students will face difficulty to understand a text if they refuse to improve their vocabulary knowledge (Chall \& Jacobs, 2003). This study was conducted to find ways to help learners overcome this difficulty. Thus, instead of engaging learners in tasks that require them to make unsupported and uninformed assumptions, learners are trained to acquire vocabulary through a more supportive teaching and learning technique that uses not only text but visual information as well. In this research, learners were taught using four types of cloze-task-based activities with varying levels of pedagogical support to find out which of them significantly helped learners understand and acquire vocabulary. As a result, the problem of applying which methods in testing are consistent with communicative language through functional pragmatic testing (cloze-based tests) has arisen among teachers. It occurs when learners are given the opportunity to generate vocabulary in the cloze-tasks they take, rather than memorising or simply choosing the right word from a list of options presented, as is the case in most multiple-choice tests.

As a result, the current study is concerned with variants of cloze-test-based tasks in assessing primary school learners' vocabulary achievement.

\subsection{Research Objectives}

The objectives of this study are to:

1) determine the cloze-based variants that significantly help learners in the vocabulary achievement.

2) investigate how the variants of cloze-test based tasks contribute to learners' vocabulary achievement.

\subsection{Research Questions}

Based on the objectives of the study, the following questions are raised:

1) Which one of the cloze-test based variants that significantly help learners in their vocabulary achievement?

2) How do these cloze-test based tasks variants contribute to learners' vocabulary achievement?

\section{Literature Review}

\subsection{Vocabulary Knowledge}

According to Nation (2001), possessing vocabulary knowledge means being able to recognise word items and to understand the various features of word items. It is also explained that item knowledge is described as the individual word or type of the word, and this knowledge requires a person to understand different characteristics of the word such as phonological, orthographical and semantic. Next, Thornburry (2002) explains that there are two types of vocabulary which are receptive vocabulary and productive vocabulary:

i. Receptive Vocabulary. Receptive vocabulary refers to the words that students know when they hear, when they read or when they interpret the words they know. Receptive vocabulary can be considered as passive vocabulary. Some approaches may be engaged to improve receptive vocabulary ability. One of the approaches is to mention some words and to find their synonyms and antonyms. 
ii. Productive Vocabulary. Productive vocabulary refers to the words used by students when talking or writing and is termed as an active vocabulary. Learners should try to speak and write much to increase this active vocabulary skill.

Vocabulary knowledge also means learners understand the words in detail, including spelling, pronunciation, syntax, sound structure and collocation based on contexts (Qian, 2002). Understanding a word means understanding how to use it in a specific text or context rather than its actual meaning. Thus, vocabulary in language learning should not be considered just as a single dimension, but as a multidimensional area. The theory is also reinforced by Antonacci and O'Callaghan (2012), who clarify that knowledge of vocabulary involves aspects such as word recognition where the learner knows the meaning of words, reads or writes, and the learner is able to understand the full meaning of the word and communicate about different meanings of the word.

\subsection{Vocabulary Teaching}

In second language learning and instruction, vocabulary is one of the most important skills. This is the foundation of all other skills: comprehension reading, comprehension listening, speaking, writing, spelling and pronunciation. It is necessary to consider all aspects of vocabulary learning in an ESL classroom when referring to this declaration. Recent research has shown that vocabulary teaching can be a problem because in many schools, teachers do not feel confident enough about the best practices in vocabulary teaching and often do not know where to start training words, especially in the teaching of the second language learners (Berne \& Blachowicz, 2008).

Thornburry (2002) states that word-learning is a crucial element of language learning since languages are word-based. Therefore, a language without words is practically impossible to learn as communication between people is based on words in real life. Teachers, as well as learners, accept that vocabulary learning is a key factor in language teaching (Walters, 2004). It is important to teach vocabulary effectively to produce ESL learners who can apply language knowledge in different forms, such as in writing and speaking. Teachers often face problems and difficulties to obtain satisfactory results in teaching (Mofareh Alqatahni, 2015). These problems may be caused by the improper teaching strategies which do not match learners' background and level of proficiency. An effective teacher should therefore improve himself or herself with diverse and up-to-date vocabulary teaching strategies along with suitable methods to formatively assess learners' vocabulary achievement. Mofareh Alqatahni (2015) also points out the need for teachers to master the teaching content so that learners able to understand new vocabulary as well as engage themselves in the teaching and learning activities. In addition, the teacher should blend more than one technique when presenting a vocabulary item.

\subsection{Cloze-test Based Passage}

\subsubsection{Fixed-Deletion}

In fixed-deletion, after one or two sentences, every word is deleted consistently. To be specific, the teacher will fix the position of the deleted word of phrases in a particular sentence. The intervals of the deleted word will be fixed in all sentences in a paragraph. This procedure, known as fixed ratio method, results in the most commonly used and the best researched type of cloze task.

It seems that the greater the number of words between two deletions, the easier the guessing of the missing word because more contextual clues are available to task takers. However, in a study conducted by Alderson (1980) such an expectation was rejected. He administered two cloze tasks to a particular group. One task had a $6^{\text {th }}$ word deletion pattern and the other had a $12^{\text {th }}$ word deletion pattern. He found out that there was no significant difference between the means of two sets of scores. He concluded that "increasing the amount of context on each side of a cloze gap beyond 5 words had no effect on the ease with which that gap would be clozed on the average" (p. 66). This finding confirms the findings by Kleijn (2018) that increasing the context beyond four words has no effect on the predictability of a word.

\subsubsection{Rational Deletion}

Rational cloze involves teacher selecting particular items, diverges somewhat from fixed-deletion, which relies on regular sampling of words in the text. A rational cloze refers to one whereby a specific type of word is deleted, for example, verbs or adjectives (Thompson, 2001). That is, the teacher may decide to leave out certain parts of speech such as all verbs, or prepositions. In other words, rational deletion is also known as selective deletion where the teacher is responsible to select words to be deleted systematically based on the subject, theme, or even part of speech.

To specify, in the selective deletion or rational cloze, the tester chooses which items to be deleted from the text. The goal for teachers using this test is not only to fine-tune the level of difficulty of the text, but also to measure the knowledge of specific grammatical points and vocabulary items.

\subsection{Multiple-choice Items}

Multiple-choice items are commonly used to assess language achievement among ESL learners. Due to its flexibility items are easy to construct and match with the learning outcomes, and hence most educators prefer to devise multiple-choice items. Brown (2004) describes multiple-choice items as either selective or receptive. In referring to this, the learners are required to choose from a 
set of answers rather than giving their own answer.

While this has come into recent prominence, the standardised task which is mostly multiple-choice is still seen as the most common and possibly the most affordable type of tasking. It is highly believed that a task or test that involves multiple-choice questions is basically employed to assess vocabulary (Heaton, 1990). This statement is supported by a study conducted by Toksoz and Ertune (2007) who asserted that multiple-choice items seemed to be effective in terms of item facility. In this study, 435 learners sat for a multiple-choice test which consisted of vocabulary and grammar items. The results of this study showed that the vocabulary items were relatively reliable and valid based on the value of consistency achieved, ranged between .60 and .85. As Brown (2004) states, easy items can function as warm-up items and indirectly motivate the learners especially the low achieving learners. Teaching of grammar and teaching vocabulary are two important lessons of learning a second language, and it is necessity to use multiple-choice items because of their advantage in fulfilling the content validity and this helps the learners to perform in area that is being assessed (Mousavi, 2002).

Although multiple-choice items have been widely used in developing English language task, these items have disadvantages and weaknesses too. Brown (2004) mentions that it is difficult to design multiple-choice items accurately. Another disadvantage of multiple-choice items in language tasking is it only measures recognition knowledge which is considered as a low mental skill based on Bloom's taxonomy (Hughes, 2003). In other words, learners might guess the answers of the questions rather than using their own knowledge to find the correct answer. This is also known as guessing which probably might have effects on the test scores. Multiple choice tasks also expose learners to misinformation that can influence subsequent thinking about the content (Weimer, 2015).

A research done by Ozturk (2007) revealed that the English Language teachers made much more mistakes in vocabulary section than the other sections of a particular task. Thus, the results portrayed even though English teachers have been provided with the inputs of constructing multiple-choice items in advance during their training and courses, the teachers still construct improper items despite language task is an important role in both teaching and learning process. Well-constructed tests can enhance learning and motivate learners. This research shows the importance for the teachers to have adequate knowledge and skills in constructing coherent and proper items in assessing vocabulary to increase the quality of teaching and learning.

\subsection{Pictures}

In the teaching of English as a second language, teachers play an important role to choose and decide the teaching instructions suitable for their learners. The effectiveness of the instructions implemented in teaching and learning process ensure language learning and increase capability in language skills either in spoken or written medium. One of the most effective strategies that have been used in language learning is the use of pictures as stimulus, clues or even meaning representation of new vocabulary.

Carry (2011) explained that teachers must use images to increase comprehension. In her presentation, she introduced visual literacy whereby learners analysed the visual texts and socio-cultural contexts by using their critical thinking. The purpose of using visual literacy was to enable learners use their critical thinking skills such as exploring, critiquing, and reflecting to make meaning from pictures. It is important to note that when the learners manage to critically observe any visual of picture given in a particular task, he or she will be able to make meaning partially of the text given. This is supported by a study done by Vedyanto (2006) which implies correlation between picture use in task format and learners' vocabulary achievement in Santu Petrus Junior High School in Indonesia. In this study, it was found out that pictures had positive impacts on the seventh graders' vocabulary achievement. Apart from that, through observation, it was discovered that the selected learners showed positive attitudes such as enjoyment, confidence and concentration in completing the task with pictures. This shows that visual elements have the ability to improve language learning as learners will concentrate more on pictures. Rokni \& Karimi (2013) elaborated that the use of visual aids like pictures plays a significant role for enhancing teaching and learning process of vocabulary.

\section{Methodology}

This section discusses the research design, research participants, instruments and data collection procedure.

\subsection{Research Design}

This study employed a multi-methods design. The first part of the study consisted of quantitative data from the scores obtained by the research participants in the tasks and the second part consisted of qualitative data from the semi-structured interview with research participants. The data was collected in April, 2018 in five different schools located in Sabah, Malaysia. The schools were selected based on their locality in suburban area of Sabah, Malaysia. This study started off with a single-group design but to overcome the issue of validity and reliability, multiple groups were included. To triangulate the data of this study, multiple groups were included to answer the research questions set earlier.

\subsection{Research Participants}

The research participants of this study were the Year 5 
primary school learners who learned English language as their second language at school. The proficiency level of the learners ranged from low to intermediate. The level of proficiency in English language was analysed based on the learners' March, 2019 monthly test. The research participants were chosen by the technique of purposive sampling. In purposive sampling, the research participants were selected according to certain similar characteristics such as they were at low to intermediate level of proficiency, same age, similar family background, English second learners and they faced difficulties in using full English as the language of interaction during English lesson. According to Sevik (2012) states purposive sampling, which is also known as subjective or selective sampling, is a non-probability technique of sampling. Patton (1990) claims that purposive sampling is suitable for both quantitative and qualitative research.

\subsection{Instruments}

\subsubsection{Cloze-Test Based Tasks}

The instruments used in the current study were the cloze-test based tasks. The aim of using these tasks was to assess the participants' vocabulary knowledge. In detail, the content of the tasks was taken from the Year 5 textbook. The format of the cloze passages used was rational cloze. Rational cloze is different from random cloze as in rational cloze, deletions in a passage are selectively done rather in random cloze, the deletions of words are randomly done in a variety of ways. The rational cloze procedure in this study was similar with other rational cloze measure. To be specific, the types or group of words that were deleted were similar; content words (nouns, verbs, adverbs, adjectives). Four sets of vocabulary tasks were designed as instruments.

Table 1. Features of the Cloze-Test Based Task.

\begin{tabular}{|c|cc|}
\hline $\begin{array}{c}\text { CLOZE-TEST BASED } \\
\text { VARIANT }\end{array}$ & Features \\
\hline \multirow{2}{*}{ One } & Cloze-passages & $\sqrt{ }$ \\
& Pictures & \\
& Multiple Choice Items \\
\hline \multirow{2}{*}{ Two } & Cloze-passages & $\sqrt{ }$ \\
& Pictures (General Pictures) & $\sqrt{ }$ \\
& Multiple Choice Items & \\
\hline \multirow{2}{*}{ Three } & Cloze-passages & $\sqrt{ }$ \\
& Pictures (Individual & $\sqrt{ }$ \\
& Pictures) & \\
\hline \multirow{2}{*}{ Four } & Multiple Choice Items & $\sqrt{ }$ \\
& Cloze-passages & $\sqrt{ }$ \\
\hline
\end{tabular}

Table 1 shows the features of all the four cloze-test based tasks administered to the research participants in the current study.

\subsubsection{Semi-structured Interview}

Next, semi-structured interview was used as an instrument in this study. To employ this instrument, ten research participants were randomly selected to answer a set of questions with the aim to obtain additional clarification and information of the different features of cloze-test based tasks. In this instrument, both close-ended and open-ended questions were used to ask questions to the research participants. During the interview, a set of standardised questions were asked to the research participants. The responses or answers received during the interview sessions were recorded in writing form. It is important for the researcher to write the important points during the interview process (Merriam, 1998).

\subsection{Data Collection Procedure}

The research participants of this study were selected from five different schools in Sabah, Malaysia. First, the consents of the headmasters of the selected schools were obtained for the research to take place in the schools. Next, the English teacher of each school selected one class of Year 5 learners to be tasked. The research participants were given 30 minutes to answer each of the tasks in four different days. Their task papers were immediately collected after they had completed them within the time allocated. To ensure the inter-reliability of the data, the task papers were marked by the researcher and two other teachers to check for research participants' achievement in all of the tasks.

After the research participants answered all the tasks given, 10 out of 135 research participants were selected randomly to be interviewed regarding their perceptions on the variants of cloze-test based tasks given. The interview session was conducted individually. To ensure and maintain the accuracy or the interpretations, member-checking was performed with participating teachers. They were required to read through the transcripts and data analysis.

\subsection{Data Analysis}

\subsubsection{Cloze-test based tasks}

The results obtained were presented in percentage form. Goh (2012) explains that descriptive statistics presents quantitative data in measures like percentage. The main purpose of the quantitative data is to eliminate or minimise subjectivity of judgment. The quantitative data also precisely specify both the independent and dependent variables under a particular research. The scores via the cloze-test based tasks were analysed using the following formula: 


$$
\text { Marks }=\frac{\text { Total scores }}{\text { Number of questions (20) }} \times 100 \%
$$

(Harris, 1996)

The tasks were given with the aim to measure learners' understanding and acquisition of the given vocabulary and to investigate which task is effective in helping learners understand and acquire vocabulary. The results for different variants of the tasks were presented in the form of a statistical report of percentage and described on the graphic form. Next, a table of categorisation of scores was used to group the research participants' acquisition level of vocabulary as in Table 2 .

Table 2. Primary School Range of Marking Score

\begin{tabular}{|c|c|}
\hline Ability Level & Range of Score \\
\hline Excellent & $80 \%-100 \%$ \\
\hline Good & $65 \%-79 \%$ \\
\hline Satisfaction & $50 \%-64 \%$ \\
\hline $\begin{array}{c}\text { Attained the Minimum } \\
\text { Standard }\end{array}$ & $40 \%-49 \%$ \\
\hline $\begin{array}{c}\text { Have not attained the Minimum } \\
\text { Standard }\end{array}$ & $0 \%-39 \%$ \\
\hline
\end{tabular}

(Ministry of Education, 2018)

Table 2 shows the categorisation of scores used in Malaysian primary school examination system.

\subsubsection{Semi-structured Interview}

The data gathered from the semi-structured interview was analysed by categorising the information gathered. Some might call this process 'coding' the data. This process involves certain steps such as reading the data and giving codes/labels to the themes from the interview responses or answers. The data analysed was in written form and descriptive statements were recorded in order to answer the research questions.

\section{Findings and Discussion}

\subsection{Findings}

In this study, the findings refer to the scores obtained by the research participants in the four tasks given where each task came with different features and to verify the scores obtained, a semi-structured interview was conducted to get additional information. The findings of the analysis were discussed in close reference to the research questions.

\subsubsection{Cloze-test based task variants that help learners achieve significantly}

The first research question concerns with which cloze-test based task variants helped learners significantly in the task given.

Table 3 shows the overall distribution of marks among the 135 learners from five different schools. Subsequently, the learners showed better results in Task 4 as being compared to the other tests. In detail, for the first ability which is 'Excellent' with the range of score between $80 \%$ to $100 \%$, a significant number of $14(10 \%)$ learners achieved this level of ability, 7(5\%) learners in Task 3 and Task 2 (2\%) learners in Task 2. It is important to note that there was no learner in this level in Task 1. Meanwhile, for the ability level of 'Good' with the range of score between $65 \%$ to $79 \%$, there were $22(16 \%)$ learners in Test 4, $8(6 \%)$ learners in Task 3, $12(9 \%)$ learners in Task 2 and $1(1 \%)$ learners in Task 1 . Next, for the ability level of 'Satisfaction' with the range of score between $50 \%$ to $64 \%$, there were $40(31 \%)$ learners achieved this level in Task 4, 35 (26\%) learners in Task 3, 18 (13\%) learners in Task 2 and $9(7 \%)$ learners in Task 1 . For the ability level of 'Attained the Minimum Standard', there were 30 (22\%) learners respectively were in this ability level in Task 4 and Task 3, 29 (21\%) learners Task 2 and $14(10 \%)$ learners in Task 1. Finally, the majority of the learners had not attained the minimum standard in Task 1 with 111 (82\%) learners, $74(54 \%)$ learners in Task 2, 55 (41\%) learners in Task 3 and 29 (21\%) learners in Task 4. Based on the results reported in Table 3, the learners achieved most significantly in Task 4 as compared to the other tasks. Hence, the variants of cloze-test based tasks that helped learners significantly in this study were cloze-passages, visual aids in the form of general pictures and Multiple-Choice Items (MCI) and this answers the first research question.

Table 3. Overall Scores Obtained by the Research Participants-135 Learners

\begin{tabular}{|c|c|c|c|c|c|}
\hline \multirow{2}{*}{ Ability Level } & \multirow{2}{*}{ Range of Score } & \multicolumn{4}{|c|}{ Frequency and Percentage } \\
\cline { 3 - 5 } & & TASK 1 & TASK 2 & TASK 3 & TASK 4 \\
\hline Excellent & $80 \%-100 \%$ & & $2(2 \%)$ & $7(5 \%)$ & $14(10 \%)$ \\
\hline Good & $65 \%-79 \%$ & $1(1 \%)$ & $12(9 \%)$ & $8(6 \%)$ & $22(16 \%)$ \\
\hline Satisfaction & $50 \%-64 \%$ & $9(7 \%)$ & $18(13 \%)$ & $35(26 \%)$ & $40(31 \%)$ \\
\hline $\begin{array}{c}\text { Attained the Minimum } \\
\text { Standard }\end{array}$ & $40 \%-49 \%$ & $14(10 \%)$ & $29(21 \%)$ & $30(22 \%)$ & $30(22 \%)$ \\
\hline $\begin{array}{c}\text { Have not attained the } \\
\text { Minimum Standard }\end{array}$ & $0 \%-39 \%$ & $111(82 \%)$ & $74(54 \%)$ & $55(41 \%)$ & $29(21 \%)$ \\
\hline
\end{tabular}




\subsubsection{Cloze-test based tasks variants contributions to learners' vocabulary achievement}

The second research question is concerned with the cloze-test based tasks contributions to learners' vocabulary achievement. According to the results in Table 3, most learners scored higher marks in Task 4 as being compared to the other tasks. In Task 4, a few variants were used in the task by the researcher; cloze-passages, visual aids in the form of general pictures and Multiple-Choice Items (MCI). In order to validate the results and elicit specific information of learners' perceptions about the cloze-test based tasks variants contributions to their vocabulary achievement, semi-structured interviews were carried out to 10 learners. Hence, from the interview session, the transcriptions and the notes were analysed and the themes of the interview results were pictures and multiple-choice items.

The question directed to seek "Which one of the tasks given to you help you the most?" Ten out of ten interviewees stated that the features in Task 4 had helped them in answering the questions given correctly. Next, another question was asked to the learners, "What are the features in Task 4 that help you?". Most learners claimed the features of cloze-test based tasks that helped them were the pictures given and choices of answers to be selected to fill in the blanks. The last question directed to the learners was "How did these features help you in answering the task?".

\section{Pictures}

They claimed that the pictures used were helpful in terms of giving them the context of the passage. They added that the pictures increase their understanding, especially in selecting the words to fill in the blanks in the cloze-passage. They also pointed out that it is easy for them to make association between the content and flow of the passage by looking at the pictures given. They added that the pictures given help them to predict and provide practice in guessing the meaning from context. They also stated that the pictures given in Task 4 could be related to their previous experiences and that can be 'associated with places, objects, persons, events or animals of which they are familiar".

\section{Multiple Choice Items}

Apart from that, Multiple Choice Items were also used in Task 4. The learners said that MCI helped them recall the meaning of certain words that they have encountered beforehand. They also added that by choosing the correct answer for each blank in the cloze-passage, they could guess the meaning of the words based on their existing knowledge.

\subsection{Discussions}

Based on Table 3 and the interview conducted, the significant findings of the present study are that the learners achieved significant results in Task 4 as being compared to the other tasks. The first variant in Task 4 was cloze-passages. In Task 4, there were a few features used, which were cloze-passages, visual aids in the form of general pictures and Multiple-Choice Items (MCI).

It is clear that the research participants managed to answer the cloze-based tasks as they can identify the flow of the passages based on the other words given. This is also known as the adoption of contexts. Huges (2003) notes that there has been a push to test vocabulary in context because of certain concerns on the effects of tests on teaching and learning. Context can affect test-takers' performance in a positive way in that text-takers can comparatively easily get the right answer of the target words (Mei, 2007). Contexts in vocabulary positively contribute to learners' achievement.

Next, another variant that helped learners achieved significantly was visual aid. In Task 4 , four general pictures were provided to the learners for them to answer the questions given. The use of pictures appeared to help the learners to make associations between the storyline in cloze-passages and this apparently contributed to learners' achievement in the vocabulary tasks. This is supported by a similar study done by Ammatunnur Siddiqa \& Amrin Saragih (2015) by which they conducted pre and post vocabulary achievement tests to first-grade learners in one of the schools in Indonesia. In their findings, the percentage of learners who scored up to 75 increased from $17.1 \%$ to $82.8 \%$. In this study, they implemented a treatment by using pictures in explaining the meaning of the vocabulary as well as adding pictures in the post-test. In vocabulary assessment, visual aids help learners remember important information and retain as much knowledge learned previously in the teaching process (Ghulam Shabiralyani et al., 2015). Thus, using visual aids in the form of illustrations or pictures significantly improved learners' understanding as they were provided with the opportunity to make connection by observing the given pictures. In short, the data from this study also reveals that the use of pictures is relevant in tasking learners' vocabulary acquisition especially among young learners.

Besides, one of the variants that contributed imperatively to the research participants' vocabulary achievement was the use of multiple-choice items. In general, one of the variants in Task 4 was that the research participants were given choices of answers in the form of "A, B, C and D" and they chose the most appropriate answer for each sentence. Based on the quantitative data, the learners achieved most significantly in Task 4 as compared to the other tasks whereby $14(10 \%)$ learners achieved the ability level of 'Excellent', 22 (16\%) achieved the ability level of 'Good', 40 (31\%) learners achieved the ability level of 'Satisfaction and 30 (31\%) learners achieved the ability level of 'Attained the 
Minimum Standard. It might be deduced that the achievement of the learners in Task 4 was contributed by the multiple-choice items provided to them in answering the cloze-based passages. This effectiveness was possibly caused by the effect of the multiple-choice item that aroused learners' noticing the target words in the cloze-based passages. This is supported by Heaton (1990) who believes that multiple-choice questions are basically employed to determine vocabulary achievement. Shima Ghahari \& Shahid Bahonar (2008) stated that in vocabulary retention, consciousness of the target words by making informed guesses in choosing the best option or answer improve learners' learning of new vocabulary. Glosses draw learners' attention and provide an interesting vocabulary learning atmosphere of input-enhancement and consciousness-raising (Hee Ko, 2012; Pishghadam \& Ghahari, 2011). The multiple choice items were also considered as glosses. Glosses are vocabulary guides in reading by adding information beyond text. Rott and Williams (2003) suggests that the use of multiple choice glosses reduce the difficulties of insufficient context in a reading text. Moreover, glosses will assist learners to make connection between the word form to its meaning within short period of time and, thereby, consolidate the form-meaning association to be used in retrieving a word in the future (Rott \& Williams, 2003).

\section{Limitations of the Study}

Although the current study has provided some beneficial insights on the lenses of Malaysian ESL primary school learners' vocabulary achievement which was affected by specific variants of cloze-based test tasks, this study has some limitations. Limitations include the scope of this study. This study was conducted within a particular time frame. Hence, different results or findings may occur if the study was conducted over a longer time frame. Next, the findings of this study might only be relevant to the selected research participants as they were selected on the nature of purposive sampling method. Therefore, the results may not be generalised to other ESL learners in other contexts.

\section{Recommendations for Further Research}

Further research would be needed to follow up on the study focusing particularly at an individual level, as it has been shown that treating the subjects one-by-one might provide more meaningful data than group averages. A major pedagogical implication of the tests' variants used in this study could be proven helpful in learners' vocabulary achievements. Next, future researchers can make use of the cloze-test variants in assessing other language items such as grammar items. Grammar tests are highly related to the use of a cloze-task as it is easier for the examiner to identify the targeted grammar item that he or she hopes to assess formative or summative assessment.

\section{Conclusions}

To conclude, it is important to note that teachers must be able to devise an effective and coherent task to assess learners' vocabulary achievement. In this study, the researcher proved that the research participants scored well in Task 4 whereby cloze-based passages were provided alongside with context by using general pictures and multiple choice items in the form of "A, B, C and D". To be specific, this research concluded that visual aids as a stimulus improves learners' ability to make connection and association in answering vocabulary task. Apart from that, cloze-based passage is useful and relevant to be used as a measuring tool to task learners' acquisition of vocabulary especially young learners. Lastly, multiple-choice item is still seen as the most common and possibly the most affordable type of testing. To wrap up, teachers develop and increase understanding of the vocabulary tested when specific variants are presented in a task.

\section{REFERENCES}

[1] Alderson, J. C. (1980). Native and non-native speaker performance on cloze tests. Language Learning 30, 1:59-76.

[2] Ammatunnur Siddiqa \& Amrin Saragih. (2015). Improving the learners' vocabulary achievement by using pictures. Retrieved fromhttp://download.portalgaruda.org/article.php ?article $=126845 \& \mathrm{val}=3894$

[3] Antonacci, A.P., \& O'Callaghan, M. O. (2012). Promoting Literacy Development: 50 Research-Based Srategies for K-8 Learners. London: Sage Publications.

[4] Berne, J. I., \& Blachowich, C. L. Z. (2008). What reading teachers say about vocabulary instruction: Voices from the classroom. The Reading Teacher, 62(4), 314-323.

[5] Bloom, B.S. (1956). Taxonomy of Educational Objectives, Handbook I: The Cognitive Domain. New York: David McKay Co Inc.

[6] Brown, H. D. (2004). Language Assessment: Principles and Classroom Practices. White Plains, NY: Pearson Education.

[7] Cameron, L. (2001). Teaching languages to young learners. Cambridge: Cambridge University Press.

[8] Carry, D. (2011) Visual Literacy: Using Images to Increase 
Comprehension. Retrieved from https://readingrecovery.org /images/pdfs/Conferences/NC09/Handouts/Carry_Visual_L iteracy.pdf

[9] Chen, L.L., Noreiny Maarof., \& Melor Yunus. (2016). Factors Affecting ESL Reading Comprehension of Malaysian Secondary School Students. Proceedings of International Conference on Education (542-547). Malang, Indonesia:Universitas Negeri Malang.

[10] Chall, J.S., \& Jacobs, V.A. (2003). Poor Children's Fourth-Grade Slump. American Educator, Spring 2003. American Federation of Teachers Cunningham, Pat.

[11] Fotos, S, S. (1991). The Cloze Test as an Integrative Measure of EFL Proficiency: A Substitute for Essays on College Entrance Examinations. A Journal of Research in Language Studies, 41(3), 313-336.

[12] Ghulam Shabiralyani, Khuram Shahzad Hasan, Naqvi Hamad \& Nadeem Iqbal. (2015). Impact of visual aids in enhancing the learning process case research: District Dera Ghazi Khan. Journal of Education and Practice, 6(19), 226-233.

[13] Goh, L. H. (2012). A Practical Guide to Writing Your Action Research. Selangor: Penerbitan Multimedia.

[14] Haladyna, T. M. (1994). Developing and Validating Multiple-Choice Test Items. Hillsdale, NJ: Lawrence Erlbaum Associates.

[15] Haladyna, T. M. \& Downing, S. M. (1989). The validity of taxonomy of multiple-chice item-writing rules. Applied Measurement in Education. 1, 51-78.

[16] Harmer, J. (1991). The practice of English language teaching. London: Longman.

[17] Harris, D. P. (1996). Testing English as a second language. New York: McGraw-Hill.

[18] Heaton, J.B. (1990). Classroom testing. New York: Longman.

[19] Hee Ko, M. (2012). Glossing and second language vocabulary learning. TESOL Quarterly, 46, 56-79.

[20] Hughes, A. (2003). Testing for language teachers. Second Edition. Cambridge: Cambridge University Pres.

[21] Laufer, B., Elder, C., Hill, K., \& Congdon, P. (2004). Size and strength: Do we need both to measure vocabulary knowledge? Language Testing, 21(2), 202-226.

[22] Mei, C. (2007). Influence of contexts on vocabulary testing. US-China Education Reform. 4(7), 42-47.

[23] Merriam, S. B. (1998). Qualitative research and case study applications in education. San Francisco: Jossey-Bass Publishers. Oxford: Routledge.

[24] Ministry of Education. (2011). Primary English language curriculum. Putrajaya: Bahagian Pembangunan Kurikulum: Kementerian Pelajaran Malaysia.

[25] Ministry of Education Malaysia. (2018). School Examination Analysis System. Retrieved from https://sapsnkra.moe.gov.my/dokumen/GRED.pdf

[26] Mousavi, S. A. (2002). An encyclopedic dictionary of language testing. Third edition. Taiwan: Tung Hua Book
Company.

[27] Mustafa Sevik. (2012). Teaching Listening Skills to Young Learners through 'Listen and Do' Songs. Retrieved from http://www.sciencedirect.com/science/article/pii/S1877042 814061734

[28] Nation, I. S. P. (1990). Teaching and learning vocabulary. Boston, Mass.: Heinle \& Heinle Publishers.

[29] Nation, I. S. P. (2001). Learning vocabulary in another language. Cambridge: Cambridge University Press.

[30] Oller J W. (1971). "Dictation as a Device for Testing ESL Proficiency, English Language Teaching, 25, 254-259.

[31]

[32] Öztürk, M. (2007). Multiple-Choice Test Items of Foreign Language Vocabulary. Eğitim Fakültesi Dergisi, 20 (2), $399-426$.

[33] Patton, M. (1990). Qualitative evaluation and research methods. Retrieved from http://legacy.oise.utoronto.ca/rese arch/field-centres/ross/ctl1014/Patton1990.pdf

[34] Paul, K. (2007). Linguistic Innovators: The English of Adolescents in London: Full Research Report ESRC End of Award Report, RES-000-23-0680. Swindon: ESRC

[35] Pishghadam, R. \& Ghahari, S. (2011). The impact of glossing on incidental vocabulary learning: A comparative study. Iranian EFL Journal, 7, 8-29.

[36] Qian, D. D. (2002). Investigating the relationship between vocabulary knowledge and academic reading performance: An assessment persepective. Language Learning, 52(3), 513- 536. doi:10.1111/1467-9922.00193

[37] Read, J. (2000). Assessing vocabulary. United Kingdom: Cambridge University Press.

[38] Richards, J. C., and Rodgers, T. (2001). Approaches and Methods in Language Teaching. Second Edition. New York: Cambridge University Press.

[39] Rokni, S. J. A., \& Karimi, N. (2013). Visual Instruction: An Advantage or A Disadvantage? What about Its Effect on EFL Learners' Vocabulary Learning? Asian Journal of Social Sciences and Humanities, 2(4), 236-243.

[40] Rott, S., \& Williams, J. (2003). Making form-meaning connections while reading: A qualitative analysis of word processing. Reading in a Foreign Language, 15, 183-222.

[41] Schmitt, N. (1999). The relation between TOEFL vocabulary items and meaning, association, 325 collocation, and word-class knowledge. Language Testing 16, 189-216.

[42] Shepherd, B. (2014). Vocabulary Assessment With Varying Levels of Context: A Replication Study. The Catesol Journal, 2(5), 1-23.

[43] Shima Ghahari. \& Shahid Bahonar. (2008). An intensive strategies-based program: insights for literacy and socio-emotional growth of college-level learners. Asian-Pacific Journal of Second and Foreign Language Education, 2(9), 20-29.

[44] Stallman, A.C., \& Anderson, R., Schommer, M., Scott, J.A., \& Nagy, W. E.(1989). Morphological families and word recognition. Reading Research Quarterly, 24, 262-282. 
[45] Kleijn, S. (2018). Clozing in on Readability: How linguistic features affect and predict text comprehension and online processing. Netherlands: LOT Trans 10.

[46] Thompson, M. (2001). Putting learners to the test. Issue Twenty. Forum. July

[47] Thornburry, S. (2002). How to teach vocabulary. England: Pearson Education Limited.

[48] Toksoz, S. \& Ertune, A. (2017). Item Analysis of a Mutiple-Choice Exam. Advances in Language and Literary Studies, 8(6), 141-146.

[49] Vedyanto. (2016). Correlation between Picture Use in Test Format and Learners' Vocabulary Achievement. Advance in
Language and Literary Studies, 7(1), 54-59.

[50] Walters, J.D. (2006). Methods of teaching inferring meaning from context. RELC Journal, 37(2), 176-190.

[51] Weimer, N. (2015). Advantages and Disadvantages of Different Types of Test Questions. Retrieved from https://www.facultyfocus.com/articles/educational-assessm ent/advantages-and-disadvantages-of-different-types-of-test -questions/

[52] Zimmerman, C. B. (1997). Historical trends in second language vocabulary insfruction. In J. Coady and T. Huckin (Eds.), Second language vocabulary acquisition. U.S.A: Cambridge University. 